\title{
Hesitation regarding the COVID-19 vaccine among medical students in Brazil
}

\author{
Ítalo Emanoel de Sousa Chaves (10, Paulo Roberto Pinheiro Brito' (1), \\ João Guilherme Bentes de Araújo Rodrigues ${ }^{2}$ (D), Milena Silva Costa' ${ }^{10}$, \\ Estelita Lima Cândido ${ }^{10}$, Maria Rosilene Cândido Moreira ${ }^{1 *}$
}

\section{SUMMARY}

OBJECTIVE: This study aims to know the main determinants of hesitation to the vaccine against COVID-19 mentioned by medical students in Brazil.

METHODS: A cross-sectional study with 250 students who answered the online questionnaire between December 18, 2020 and January 8, 2021. RESULTS: Most students (84\%) mentioned the intention to take anti-COVID vaccine and $14 \%$ were hesitant. Information provided by governments (59.2\%), the pharmaceutical industry (54.4\%), and the press (51.6\%) were the items that most generated vaccine hesitation. CONCLUSION: In the context of the COVID-19, vaccine hesitation is an additional concern because adherence to vaccination is a recurring challenge. The category of contextual influences predominated among the main determinants of anti-COVID vaccine hesitation expressed by medical students in Brazil, disfavoring vaccine adherence in this public.

KEYWORDS: COVID-19. Vaccination refusal. Health literacy. Students, medical.

\section{INTRODUCTION}

The vaccine against COVID-19 is the preventive measure most awaited by the global population. Immunizers are being developed using various technological platforms, such as messenger RNA, and synthetic and modified particles, such as viruses, among others ${ }^{1}$, originating immunobiologicals with different mechanisms of action for the same purpose.

The dissonance in this context is that a vaccine takes at least an average of 10 years to be released for consumption ${ }^{2}$, which was not the case with anti-COVID vaccines. As a result, the increasing speculation contributed to raising doubts and divided opinions about accepting or refusing the vaccine.

In Brazil, the acceptance of vaccines has been decreasing since 2016, which may be due to experiences with vaccination, low health literacy, perception of the pharmaceutical industry, and lack of information. As a result, vaccine-preventable diseases have increased in different Brazilian regions ${ }^{3}$.

Vaccination hesitancy, defined as the delay in accepting or refusing vaccination ${ }^{4}$, is an additional concern in the context of COVID-19. This is because vaccination adherence is a recurrent challenge in different segments of society, including Brazilian health professionals, which is verified by the low vaccine coverage against diseases such as hepatitis $\mathrm{B}^{5}$.

Although health care professionals and students have basic training on vaccines in general, a recent review study with medical students ${ }^{6}$ revealed a lack of knowledge about their own vaccine status. Another study ${ }^{7}$ with 39 physicians and 53 students from a medical school in Brazil found that most were in favor of nonmandatory vaccination, considering it reasonable

\footnotetext{
'Universidade Federal do Cariri, Medical School - Barbalha (CE), Brazil.

${ }^{2}$ Hospital Regional do Cariri - Juazeiro do Norte (CE), Brazil.

*Corresponding author: rosilene.moreira@ufca.edu.br

Conflicts of interest: the authors declare there are no conflicts of interest. Funding: Pró-reitoria de Pesquisa, Pós-graduação e Inovação at the Universidade Federal do Cariri - PRPI/UFCA (Edital 08/2019/PRPI - Apoio a Projetos de Pesquisa).

Received on July 16, 2021. Accepted on July 18, 2021.
} 
to respect the desire of someone who refused to have themselves or their children vaccinated.

According to the National Curricular Guidelines for medical programs in $\mathrm{Brazil}^{8}$, students must experience health services from the early semesters, thus being exposed to a higher risk of immunopreventable diseases. Intensified by the COVID-19 pandemic, this problem raised the following question: how do medical students formulate their opinions regarding antiCOVID vaccination? The importance of exploring this topic lies in the fact that their vaccination aims at both protection against contamination during the program's practical activities and their inclusion in the taskforce of health professionals working during the pandemic.

Moreover, even knowing that vaccine hesitancy varies according to the time and is specific to each context and that vaccine literacy resulting from necessary information ensures the right and autonomy in decision-making', this study identified the main determinants of hesitancy regarding the COVID-19 vaccine reported by medical students in Brazil.

\section{METHOD}

This cross-sectional study uses the opinion survey method without identification of participants, as provided for in Resolution 510/2016 of the National Health Council, which was conducted by posting an electronic questionnaire and a request for disclosure on a fanpage of directories of medical students. Virtual snowball sampling, which uses social media for data collection, was employed.

Data collection began on December 18, 2020, after the Supreme Court ruled that COVID-19 vaccination would be compulsory in nature in Brazil, and ended on January 8, 2021, when the Butantan Institute and Fiocruz submitted an authorization request to Anvisa for the emergency use of the CoronaVac/Sinovac and Oxford/AstraZeneca vaccines in Brazil.

The data obtained from the questionnaires were analyzed using BioEstat 5.0 software. Descriptive statistics, Pearson's chisquare, and G-tests (Wiliams) were used to evaluate the associations between the variables, and the results were classified according to the three categories of influences proposed by the World Health Organization (WHO) Matrix of Determinants of Vaccine Hesitancy:

(1) contextual, encompassing aspects of communication mediated by influential people, policy, and perception of the pharmaceutical industry;

(2) individual and group, through personal or family experiences with vaccines; and

(3) vaccine/vaccination-specific, encompassing topics related to immunizers ${ }^{4}$.

\section{RESULTS}

The study included 250 students, of which $58.5 \%$ ( $\mathrm{n}=147)$ were females, aged between 18 and 25 years $(n=209 ; 83.6 \%)$, belonging to the basic cycle $(\mathrm{n}=125 ; 50.0 \%)$, clinical cycle $(\mathrm{n}=102 ; 40.8 \%)$, and internship $(\mathrm{n}=23 ; 9.2 \%)$ and attending public higher education institutions (HEIs) ( $\mathrm{n}=146 ; 58.4 \%)$. The Northeast region had the highest percentage of participants $(n=125 ; 50 \%)$, followed by the Southeast $(n=66 ; 26.4 \%)$, South ( $\mathrm{n}=17 ; 6.8 \%)$, North $(\mathrm{n}=14 ; 5.6 \%)$, and Midwest $(\mathrm{n}=08$; $3.2 \%$ ). Cases of COVID-19 or infected family members were reported by $66.4 \%$ of students, and $35.2 \%$ said they knew someone who had died from the disease.

Most students (84\%) expressed the desire to be vaccinated, and $14 \%$ were hesitant. Information provided by governments $(59.2 \%)$, the pharmaceutical industry $(54.4 \%)$, and the press $(51.6 \%)$ were the items that caused most vaccine hesitancy. Conversely, $93.2 \%$ of the participants showed confidence in the development process of anti-COVID vaccines, and $66.4 \%$ were in favor of mandatory vaccination (Figure 1).

Students from public and private HEIs reported doubts about the new coronavirus ( 61 and $64.4 \%$; $\mathrm{p}=0.0004$ ) but stated that they would have the vaccine when it became available to the population ( 89 and $76.9 \%$; $\mathrm{p}=0.04$ ) (Table 1 ).

\section{DISCUSSION}

The main determinants of hesitancy regarding the COVID-19 vaccine revealed the great variety of aspects that influence how the medical students viewed vaccination.

Similar to other studies ${ }^{10}$, the high percentage of students in favor of vaccination indicates confidence in immunobiologicals and the perception of risk of acquiring the disease when not immunized. Conversely, differing from other studies ${ }^{11}$, the hesitant students cited topics peculiar to the pandemic scenario in Brazil, highlighting political issues involving access to vaccines, which demonstrates that contextual influences overlay individual and specific experiences of vaccination.

Although these results are encouraging when compared to those in a medical school in the United States, where 23\% were undecided ${ }^{12}, 2 \%$ of students who were against vaccination should be considered. This may be due to the anti-vaccination movement, which, although having greater influence in North America and Europe, may constitute a potential barrier to the effectiveness of vaccination in Brazil ${ }^{13}$. When attending health services in training activities, these students are more vulnerable to contagion when they are not vaccinated and are potential hidden reservoirs for COVID-19 ${ }^{14}$.

Contextual influences were expressed through the low level of confidence in some information media in Brazil, with 


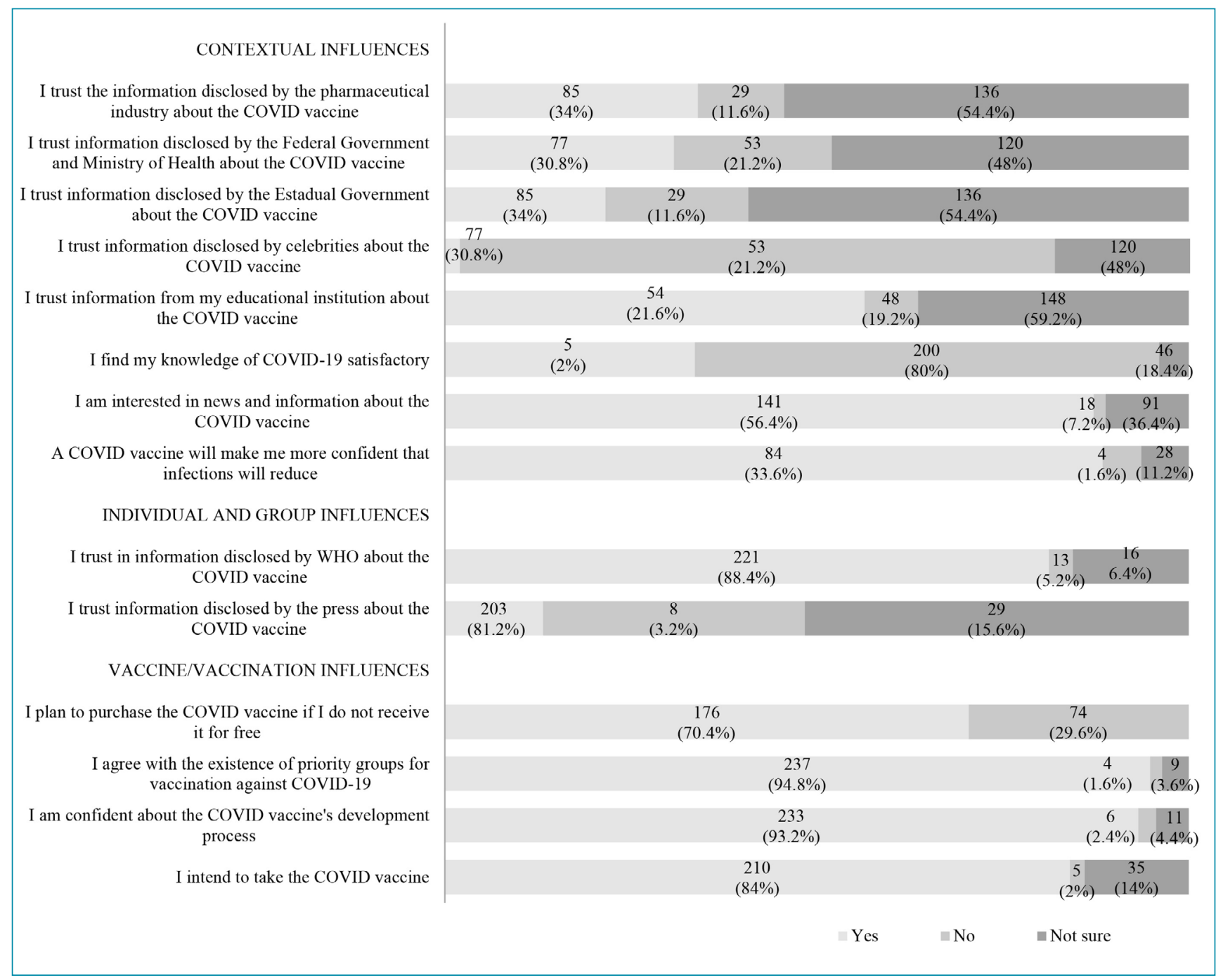

Figure 1. Vaccine acceptance, refusal, and hesitancy among medical students.

hesitancy being mostly attributed to the pharmaceutical industry and the three spheres of government. Similar to the results revealed in a study with Americans, this aspect, which considered the support from the government of the country as a way to increase the acceptance of vaccination ${ }^{15}$, surpasses the technical and individual limits of the vaccine decision processes and establishes deep interfaces with economic and political issues.

Students considered HEIs reliable sources of information about COVID-19. These findings support the social responsibility agenda of these institutions, which are strategic locations for the promotion of educational interventions that increase behavioral trust in this group ${ }^{16}$, as adolescents and young adults are included as an eligible group for vaccination in some Brazilian states.

Knowledge about COVID-19 and interest in the topic also exerted a contextual influence on the students. These results are similar to a study conducted in France with students from 32 medical universities. More than one-third were not confident in explaining the risks and benefits of vaccines to patients, revealing gaps in medical education ${ }^{17}$.

Information provided by the $\mathrm{WHO}$ and news reported by press media also affected the students' vaccination decisions. This lack of synchrony between information and viral contamination leads to government instability and misinformation, accelerating the epidemic outbreak and weakening trust in institutions ${ }^{18}$. Such situations, exacerbated by fake news that raise doubt on the scientific validation of vaccines, can make students less prone to follow legitimate health guidelines and take proven preventive measures ${ }^{19}$.

The students' personal reports about the existence of cases and deaths of family members from COVID-19, which was also found in other studies ${ }^{20}$, may have influenced their opinions, 
Table 1. Association between items regarding the COVID-19 vaccine and the groups of interest.

\begin{tabular}{|c|c|c|c|c|c|}
\hline Item & Groups & \multicolumn{4}{|c|}{ Answers } \\
\hline \multirow{4}{*}{$\begin{array}{l}\text { Do you consider your } \\
\text { knowledge about } \\
\text { COVID-19 satisfactory? }\end{array}$} & Type of program & Yes (\%) & Not sure (\%) & No $(\%)$ & $p$-value* \\
\hline & Public & $47(32.2)$ & $89(61.0)$ & $10(6.9)$ & 0.0004 \\
\hline & Private & $37(35.6)$ & $67(64.4)$ & 0 & \\
\hline & Total & $84(33.6)$ & $156(62.4)$ & $10(6.9)$ & \\
\hline \multirow{9}{*}{$\begin{array}{l}\text { Would you have a } \\
\text { vaccine that has been } \\
\text { authorized for use in } \\
\text { Brazil? }\end{array}$} & Type of program & Yes (\%) & Not sure (\%) & No $(\%)$ & p-value* \\
\hline & Public & $130(89)$ & $14(9.6)$ & $02(1.4)$ & 0.04 \\
\hline & Private & $80(76.9)$ & $21(20.1)$ & $03(2.9)$ & \\
\hline & Total & $210(84.0)$ & $35(14.0)$ & $05(2.0)$ & \\
\hline & Period of the program & Yes (\%) & Not sure (\%) & No $(\%)$ & p-value* \\
\hline & Basic & $103(82.4)$ & $20(16.0)$ & $02(1.6)$ & 0.68 \\
\hline & Clinical & $86(84.3)$ & $13(12.8)$ & $03(2.9)$ & \\
\hline & Internship & $21(91.3)$ & $02(8.7)$ & 0 & \\
\hline & Total & $210(84.0)$ & $35(14.0)$ & $05(2.0)$ & \\
\hline \multirow{5}{*}{$\begin{array}{l}\text { Do you trust the } \\
\text { information given } \\
\text { by our educational } \\
\text { institution about } \\
\text { COVID vaccines? }\end{array}$} & Period of the program & Yes (\%) & Not sure (\%) & No (\%) & p-value* \\
\hline & Basic & $73(58.4)$ & $46(36.8)$ & $06(4.8)$ & 0.47 \\
\hline & Clinical & $56(54.9)$ & $35(34.3)$ & $11(10.8)$ & \\
\hline & Internship & $12(52.2)$ & $10(43.5)$ & $01(4.5)$ & \\
\hline & Total & $141(56.4)$ & $91(36.4)$ & $18(7.2)$ & \\
\hline \multirow{5}{*}{$\begin{array}{l}\text { Do you consider that } \\
\text { vaccination against } \\
\text { COVID-19 should be } \\
\text { mandatory? }\end{array}$} & Period of the program & Yes (\%) & Not sure (\%) & No $(\%)$ & p-value* \\
\hline & Basic & $85(68.0)$ & $20(16)$ & $20(16)$ & 0.50 \\
\hline & Clinical & $67(65.7)$ & $13(12.8)$ & $22(21.6)$ & \\
\hline & Internship & $14(60.9)$ & $06(26.1)$ & $03(13)$ & \\
\hline & Total & $166(66.4)$ & $39(15.6)$ & 45 (18.0) & \\
\hline
\end{tabular}

*G test (Williams).

favoring vaccine acceptance, as the still persistent epidemiological panorama of COVID-19 indicates that without specific vaccine protection, the disease can quickly spread among people and cause irreparable damage to society ${ }^{21}$.

Specific aspects of the vaccine/vaccination were the factors that contributed less to hesitancy. The development of vaccines was a positive aspect for vaccine acceptance, even with some of the students disbelieving or being unsure about the manufacturing process of immunizing agents. These results differ from the hesitations that would be expected in this group, such as those reported by health professionals who mentioned side effects, vaccine efficacy, and virus mutation potential as the main determinants ${ }^{22,23}$.

None of the students indicated the acquisition of an antiCOVID vaccine with their own financial resources, if it was not provided by the public administrators, as a cause for hesitancy, but this item was rejected by some students. Situations that make it difficult to offer these vaccines include the absence of national planning, slow negotiations with manufacturers, and political disputes between the federal government and state managers. Added to the presidential discourse that presents vaccination as an individual choice and encourages the population to distrust a particular immunizing agent ${ }^{24}$, these obstacles place the pandemic in a challenging context that impact their willingness to take the vaccine, even if it is necessary to acquire it with their own financial resources.

Although most of the students agreed with the prioritization of groups for vaccination against COVID-19, some were hesitant. It is clear that a vaccination plan with priority groups was established due to the insufficient number of immunizations purchased by the federal government. However, even though it is acceptable the most vulnerable are vaccinated first, efforts 
should be made to ensure a vaccination scheme that encompasses all the population, given that, even among health professionals, coverage with the second dose is still insufficient, as it represents $55.9 \%$ of those who received the first dose ${ }^{25}$, indicating poor vaccination performance in Brazil.

Even in the face of this increasingly worrying scenario, the existence of an anti-COVID vaccine by itself will not be enough to eliminate vaccine hesitancy among populations ${ }^{24}$, as the elements involved in this process bring the confrontation between technical-scientific, sociocultural, political, and economic aspects to the core of the pandemic, resulting in the temporal unpredictability that will mark its end.

\section{CONCLUSIONS}

This study revealed multifaceted aspects that influence the opinions of medical students on the reliability of anti-COVID vaccines and acceptance of vaccination. Contextual influences were the main determinants of expressed hesitancy, to the detriment of vaccine adherence in this group. These findings indicate the need for strategies that promote vaccine literacy and vaccination, contributing to students' biosafety in teaching and learning scenarios.

\section{AUTHORS' CONTRIBUTIONS}

ÍESC: Conceptualization, Data curation, Formal analysis, Methodology, Writing - original draft, Writing - review \& editing. PRPB: Conceptualization, Data curation, Formal analysis, Methodology, Writing - original draft, Writing - review \& editing. MRCM: Conceptualization, Data curation, Formal analysis, Methodology, Writing - original draft, Writing - review \& editing. JGBAR: Formal analysis, Writing - original draft, Writing - review \& editing. ELC: Formal analysis, Writing - original draft, Writing - review \& editing. MSC: Formal analysis, Writing - original draft, Writing - review \& editing.

\section{REFERENCES}

1. Quintella CM, Mata AMT, Ghesti GF, Mata PMALT. Coronavirus vaccines (COVID-19; SARS-COV-2): preliminary review of articles, patents, clinical trials and market. Cadernos de Prospecção. 2020;13(1):3-12. http://doi.org/10.9771/cp.v13i1.35871

2. Lima EJF, Almeida AM, Kfouri RÁ. Vacinas para COVID-19: perspectivas e desafios. Resid Pediatr. 2020;10(2):1-3. http:// doi.org/10.25060/residpediatr-2020.v10n2-04

3. Sato APS. What is the importance of vaccine hesitancy in the fall of vaccine coverage in Brazil? Rev Saude Publica. 2018;52:96. https://doi.org/10.11606/S1518-8787.2018052001199

4. MacDonald NE, SAGE Working Group on Vaccine Hesitancy. Vaccine hesitancy: definition, scope and determinants. Vaccine. 2015;33(34):4161-4. https://doi.org/10.1016/j. vaccine.2015.04.036

5. Souza FO, Freitas PSP, Araújo TM, Gomes MR. Hepatitis B and anti-HBS vaccination among health workers. Cad Saude Colet. 2015;23(2):172-9. https://doi.org/10.1590/1414462X201500020030

6. Almeida AA, Neves BR, Palhares FRD, Raposo FBC, Handere $M P$, Freitas $Y O$, et al. Vaccination of medical students and the role of higher education institutions in primary prevention. Rev Med (São Paulo). 2021:100(2):112-8. http://doi.org/10.11606/ issn.1679-9836.v100i2p112-118

7. Mizuta AH, Succi GM, Montalli VAM, Succi RCM. Perceptions about the importance of vaccines and vaccine refusal in a medical school. Rev Paul Pediatr. 2019;37(1):34-40. https:// doi.org/10.1590/1984-0462/;2019;37;1;00008

8. Brasil. Ministério da Saúde. Resolução n 3, de 20 de junho de 2014. Institui Diretrizes Curriculares Nacionais do Curso de Graduação em Medicina e dá outras providências. [internet], 2014 [Cited on Jul. 16, 2021]. Available from: http://portal.mec.gov.br/index.php?option=com_ docman\&view=download\&alias=15874-rces003-14\&category_ slug=junho-2014-pdf\&ltemid=30192
9. Santos $P$, Hespanhol A. An ethical view of vaccine refusal. Rev Port Med Geral Fam. 2013;29(5), 328-33.https://doi. org/10.32385/rpmgf.v29i5.11167

10. Jain J, Saurabh S, Kumar P, Verma MK, Goel AD, Gupta MK, et al. COVID-19 vaccine hesitancy among medical students in India. Epidemiol Infect. 2021;149:e132. https://doi.org/10.1017/ S0950268821001205

11. Troiano G, Nardi A. Vaccine hesitancy in the era of COVID-19. Public Health. 2021;194:245-51. https://doi.org/10.1016/j. puhe.2021.02.025

12. Kelekar AK, Lucia VC, Afonso NM, Mascarenhas AK. COVID-19 vaccine acceptance and hesitancy among dental and medical students. J Am Dent Assoc. 2021;152(8):596-603. https://doi. org/10.1016/j.adaj.2021.03.006

13. Guimarães R. Anti-COVID vaccines: a look at public health Cienc Saude Coletiva. 2020;25(9):3579-85. http://doi. org/10.1590/1413-81232020259.24542020

14. Lim JS, Au Yong TPT, Boon CS, Boon IS. COVID-19 vaccine prioritisation for medical students: the forgotten cohort? Clin Oncol (R Coll Radiol). 2021;33(8):e359. http://doi.org/10.1016/j. clon.2021.02.013

15. Kreps S, Prasad S, Brownstein JS, Hswen Y, Garibaldi BT, Zhang B, et al. Factors associated with US adults' likelihood of accepting COVID-19 vaccination. JAMA Netw Open. 2020;3(10):e2025594. http://doi.org/10.1001/ jamanetworkopen.2020.25594

16. Tavolacci MP, Dechelotte P, Ladner J. COVID-19 vaccine acceptance, hesitancy, and resistancy among University students in France. Vaccines (Basel). 2021;9(6):654. http:// doi.org/10.3390/vaccines9060654

17. Kernéis $S$, Jacquet $C$, Bannay $A$, May $T$, Launay $O$, Verger $P_{t}$ et al. Vaccine education of medical students: a nationwide cross-sectional survey. Am J Prev Med. 2017;53(3):e97-104. http://doi.org/10.1016/j.amepre.2017.01.014 
18. Starbird K. Disinformation's spread: bots, trolls and all of us. Nature. 2019;571(7766):449. http://doi.org/10.1038/d41586019-02235-x

19. Erku DA, Belachew SA, Abrha S, Sinnollareddy M, Thomas J, Steadman KJ, et al. When fear and misinformation go viral: pharmacists' role in deterring medication misinformation during the 'infodemic' surrounding COVID-19. Res Social Adm Pharm. 2021;17(1):1954-63. http://doi.org/10.1016/j. sapharm.2020.04.032

20. Elhadi M, Alsoufi A, Alhadi A, Hmeida A, Alshareea E, Dokali $M$, et al. Knowledge, attitude, and acceptance of healthcare workers and the public regarding the COVID-19 vaccine: a cross-sectional study. BMC Public Health. 2021;21(1):955. http://doi.org/10.1186/s12889-021-10987-3

21. Sato APS. Pandemic and vaccine coverage: challenges of returning to schools. Rev Saude Publica. 2020;54:115. http:// doi.org/10.11606/s1518-8787.2020054003142
22. Mustapha T, Khubchandani J, Biswas N. COVID-19 vaccination hesitancy in students and trainees of healthcare professions: a global assessment and call for action. Brain Behav Immun Health. 2021;16:100289. http://doi.org/10.1016/j.bbih.2021.100289

23. Sun $Y$, Chen $X$, Cao M, Xiang T, Zhang J, Wang P, et al. Will healthcare workers accept a COVID-19 vaccine when it becomes available? A cross-sectional study in China. Front Public Health. 2021;9:664905. http://doi.org/10.3389/fpubh.2021.664905

24. Castro R. Vacinas contra a Covid-19:0 fim da pandemia?* Physis. 2021;31(01):e310100. https://doi.org/10.1590/S010373312021310100

25. Brasil. Ministério da Saúde (Brasil). COVID-19 - Vaccination: applied doses [internet]. 2021[cited on Jul. 16, 2021] Available from: https://qsprod.saude.gov.br/extensions/ DEMAS_C19Vacina/DEMAS_C19Vacina.html 